\title{
Clearance of Quadriceps Muscle Haematoma with Dobesilate
}

\begin{abstract}
Keywords: Quadriceps muscle; Haematoma; Dobesilate Summary

Muscle injuries are one of the most common traumas occurring in sports, often accompanied with haemorrhage. The standard of care for patients with acute intramuscular haemorrhages associated with skeletal muscle injuries is conservative therapy. In this context, we have evaluated the effectiveness of dobesilate in a patient with acute rectus femoris haemorrhage. We show for the first time that two weeks of dobesilate treatment cleared intramuscular haemorrhage and improved function in the affected thigh.
\end{abstract}

\section{Introduction}

Musculoskeletal injuries are frequent in athletes, and strains are the most common lesions, especially in sports involving running. These conditions can produce tension overload in a passive muscle or eccentric overload in an actively contracting muscle [1]. Musculoskeletal injuries vary from mild or first degree to muscle tear or third degree. In many athletes, severe muscle strains can lead to haematoma formation that cannot be prevented. Early return to activity is needed to optimize the regeneration of healing skeletal muscle and recover the flexibility of strength of the injured skeletal muscle to pre-injury levels. Here we report the resolution of haematoma and longitudinal tear of the rectus femoris following quadriceps strain, in an athlete treated with dobesilate during two weeks.

\section{Case Presentation}

A 28-year old male Caucasian athlete presented in our clinic the day after suffering quadriceps strain in his left thigh, referring painful motion loss. On physical examination, an oedema was found on the anterior surface of his affected thigh. The pain was continuous and aggravated on palpation of the quadriceps muscle and any knee movement. There was no gap in quadriceps continuity. The patient was not able to perform an isometric quadriceps contraction with his knee in full extension, being the active knee's range of movement of $40^{\circ}$. The pulse of his periphery arteries (assessed with Doppler ultrasound) was normal and his coagulation profile did not show any bleeding diathesis. Furthermore, compartment syndrome formation was not detected. Patient did not report any use of anabolic steroids. After clinical examination, a magnetic resonance imaging (MRI) study was performed to estimate the size of the muscular lesion and to evaluate the surrounding tissues. MRI pictures showed a longitudinal region of increased signals tracking along the rectus femoris muscle consistent with an intramuscular haematoma along a longitudinal tear in the rectus femoris muscle (Figure 1).

Patient was treated conservatively only with oral dobesilate

\section{Journal of}

Clinical \& Medical Case Reports

\author{
Pedro Cuevas ${ }^{1 *}$, Tomás Fernández-Jaén ${ }^{2}$, Javier Angulo- \\ Frutos $^{3}$, Adrián Cuevas-Bourdier ${ }^{4}$ and Guillermo \\ Giménez-Gallego ${ }^{5}$ \\ ${ }^{1}$ Universidad Alfonso X el Sabio, Villanueva de la Cañada, Madrid, \\ Spain \\ ${ }^{2}$ Clínica Cemtro Madrid, Spain \\ ${ }^{3}$ Departamento de Investigación, Hospital Universitario Ramón y \\ Cajal, Madrid, Spain \\ ${ }^{4}$ Laboratoire National de Santé, Dudelange, Luxembourg, Europe \\ ${ }^{5}$ Departamento de Estructura y Función de Proteinas, Centro de \\ Investigaciones Biológicas, Madrid, Spain \\ Address for Correspondence: \\ Cuevas Pedro, Facultad de Medicina, Universidad Alfonso X el Sabio, \\ Villanueva de la Cañada, Madrid, Spain; E-mail: pedro.cuevas44@gmail.com \\ Submission: 29 October, 2016 \\ Accepted: 01 December, 2016 \\ Published: 07 December, 2016 \\ Copyright: () 2016 Cuevas P, et al. This is an open access article \\ distributed under the Creative Commons Attribution License, which \\ permits unrestricted use, distribution, and reproduction in any medium, \\ provided the original work is properly cited.
}

(Doxium forte, Laboratorios Dr. Esteve, Spain; 1 g twice a day) without analgesics, for two weeks. Patient was instructed to perform strengthening exercises during treatment. He returned to our clinic for the first follow-up visit after two weeks.

\section{Results and Discussion}

After one day of treatment, the patient started to walk using crutches, although he could do without them after seven days. At the end of treatment, the active range of movement was $120^{\circ}$ and the passive one $130^{\circ}$. MRI examination was normal without any signs of haematoma (Figure 1) and he has regained a full pain-free range of movement. Patient returned to his old sport activities after two weeks of the end of treatment, which means one month after injury. No

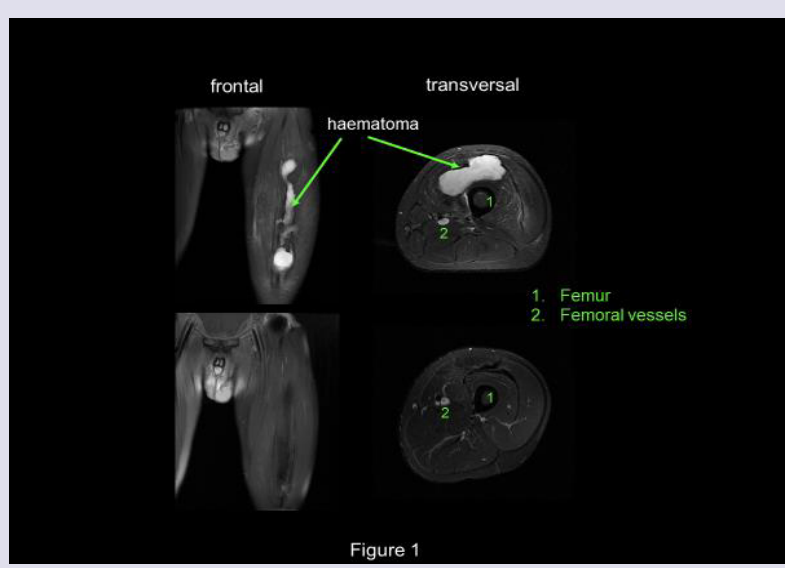

Figure 1: Magnetic resonance imaging scans at baseline shows a welldefined haemorrhage in the left rectus femoris muscle (up). After two weeks of oral dobesilate treatment (down) magnetic resonance imaging scans showed a complete resolution of intramuscular haemorrhage. 
Citation: Pedro C, Tomás FJ, Javier AF, Adrián CB, Guillermo GG. Clearance of Quadriceps Muscle Haematoma with Dobesilate. J Clin Med Case Reports. 2016;3(2): 2.

ISSN: $2332-4120$

recurrence of symptoms was observed during the two months followup examinations.

Quadriceps muscle strains frequently occur in athletes. The rectus femoris is the most susceptible to injury because of its higher content of type II myofibers, superficial location and biarticular course [1]. Haematoma formation in the quadriceps muscle rarely leads to the development of compartment syndrome [2], which is the only indication of fasciotomy and haematoma evacuation [3]. Any surgical intervention in the acute phase of musculoskeletal haematomas is contraindicated [4], thus, conservative therapy is the standard treatment of acute musculoskeletal haemorrhages.

Conventional therapy of haematoma in quadriceps strains is conservative, consisting of rest and immobilization but there are few reports in literature about haematoma evolution under these conditions. For instance, a case of quadriceps rupture with intramuscular haematoma in a child has been reported after multiple injections of clindamycin in the quadriceps muscle. The patient was placed in a long leg half-casting for three weeks. After this period, casting was taken off and the patient was symptoms free with full range of knee motion [5]. However, no images were reported in this case report regarding muscular haematoma resolution. Moreover, a case of bilateral quadriceps haematoma in a female athlete was treated with bandaging, ice application, rest, elevation and administration of muscle relaxant drugs. Six weeks later, patient had pain-free function and clearance of intramuscular haematoma [6]. Finally, a rugby player with vastus intermedius tendon rupture and intramuscular haematoma confirmed by MRI scans who was treated with conservative therapy required five months to train with the team again [7]. The evidence provided by these case reports is supported by other publications reporting that, in intramuscular haematoma, return to sport activity is generally not possible before a period of 10-20 weeks [8]. Thus, even in the cases with muscular haematoma resolution after conservative therapy, the time required for this favorable outcome was considerably longer than that reported with dobesilate treatment in the present case.

Because our laboratory studies showed that dobesilate (a drug with a long history of clinical safety) cleared haemorrhages in animal models [9], and also in ophthalmic patients [10-12], we were interested in testing dobesilate efficacy in musculoskeletal injuries. Although supporting evidence on the mechanism of curative effect of dobesilate in haemorrhages is lacking, the data shown in this report could serve as a promising new clinical application in musculoskeletal haemorrhages.

\section{References}

1. Azar FM (2003) Traumatic disorders. In: Campell's operative orthopedics. Canale TOC

2. Rööser B, Bengtson S, Hägglund G (1991) Acute compartment syndrome from anterior thigh muscle contusion: a report of eight cases. J Orthop Trauma 5: 57-59.

3. Rööser B (1987) Quadriceps contusion with compartment syndrome. Evacuation of hematoma in 2 cases. Acta Orthop Scand 58: 170-172.

4. Rothwell AG (1982) Quadriceps Hematoma. A prospective clinical study. Clin Orthop Relat Res 97-103.

5. Aydemir G, Cakmak S, Aydinoz S (2010) Partial rupture of the quadriceps muscle in a child. BMC Musculoskelet Disord 11: 214

6. Natsis K, Lyrtzis C, Noussios G, Papathanasiou E, Anastasopoulos N et al. (2010) Bilateral rectus femoris intramuscular haematoma following simultaneous quadriceps strain in an athlete: a case report. J Med Case Rep 4: 56 .

7. Cetinkaya E, Aydin CG, Akman YE, Gul M, Arikan Y, et al. (2015) A rare knee extensor mechanism injury: Vastus intermedius tendon rupture. Int J Surg Case Rep 14: 186-188.

8. Conforti M (2013) The treatment of muscle hematomas. In: Bisciotti GN, Eirale C (Eds), Muscle injuries in sport medicine. INTECH.

9. Fernández IS, Cuevas $\mathrm{P}$, Angulo J, López-Navajas $\mathrm{P}$, Canales-Mayordomo A, et al. (2010) Gentisic acid, a compound associated with plant defense and a metabolite of aspirin, heads a new class of in vivo fibroblast growth factor inhibitors. J Biol Chem 285: 11714-11729.

10. Favre M (1970) Treatment of diabetic retinopathy and recurrent hemorrhages into the vitreous with calcium dobesilate. Ophthalmologica 161: 389-393.

11. Cuevas P, Outeiriño LA, Azanza C, Angulo J, Giménez-Gallego G (2015) Dramatic resolution of vitreous hemorrhage after an intravitreal injection of dobesilate. Mil Med Res 2: 23.

12. Luo D, Qin Y, Yuan W, Deng H, Zhang Y, et al. (2015) Compound danshen dripping pill for treating early diabetic retinopathy: A randomized, doubledummy, double-blind study. Evid Based Complement Alternat Med 2015: 539185 